\title{
Relative importance of phosphatidylinositol-3 kinase (PI3K)/Akt and mitogen-activated protein kinase (MAPK3/1) signaling during maturational steroid-induced meiotic G2-M1 transition in zebrafish oocytes
}

\author{
Debabrata Das ${ }^{2,3}$, Poulomi Nath ${ }^{2}$, Soumojit Pal ${ }^{2}$, Sudip Hajra ${ }^{2}$, Pritha Ghosh ${ }^{2}$ and Sudipta Maitra ${ }^{1}$ \\ Department of Zoology, Visva-Bharati, Santiniketan, India
}

Date submitted: 16.01.2017. Date revised: 02.07.2017. Date accepted: 16.08.2017

\section{Summary}

Participation and relative importance of phosphatidylinositol-3 kinase (PI3K) and mitogen-activated protein kinase (MAPK) signalling, either alone or in combination, have been investigated during $17 \alpha, 20 \beta$-dihydroxy-4-pregnen-3-one (DHP)-induced meiotic G2-M1 transition in denuded zebrafish oocyte. Results demonstrate that concomitant with rapid phosphorylation (activation) of Akt (Ser473) and MAPK (ERK1/2) at as early as 15 min of incubation, DHP stimulation promotes enhanced an GVBD response and histone $\mathrm{H} 1$ kinase activation between 1 and $5 \mathrm{~h}$ in full-grown oocytes in vitro. While p-Akt reaches its peak at 60 to $90 \mathrm{~min}$ and undergoes downregulation to the basal level by $240 \mathrm{~min}$, ERK1/2 phosphorylation (activation) increases gradually until $120 \mathrm{~min}$ and remains high thereafter. Although, priming with MEK1/2 inhibitor U0126 is without effect, PI3K inhibitors, wortmannin or LY294002, delay the GVBD response significantly $(P<0.001)$ until $3 \mathrm{~h}$ but not at $5 \mathrm{~h}$ of incubation. Interestingly, blocking PI3K and MEK function together could abrogate steroid-induced oocyte maturation at all time points tested. While DHP stimulation promotes phospho-PKA catalytic (p-PKAc) dephosphorylation (inactivation) between 30-120 min of incubation, simultaneous inhibition of PI3K and MEK1/2 kinases abrogates DHP action. Conversely, elevated intra-oocyte cAMP, through priming with either adenylyl cyclase (AC) activator forskolin (FK) or dibutyryl cAMP (db-cAMP), abrogates steroid-induced Akt and ERK1/2 phosphorylation. Taken together, these results suggest that DHP-induced Akt and ERK activation precedes the onset of meiosis (GVBD response) in a cAMP-sensitive manner and PI3K/Akt and MEK/MAPK pathways together have a pivotal influence in the downregulation of PKA and resumption of meiotic maturation in zebrafish oocytes in vitro.

Keywords: GVBD, Oocyte, Meiosis, PKA, Zebrafish

\section{Introduction}

In teleosts, as in other lower vertebrates, before the onset of final oocyte maturation, a surge in pituitary gonadotropin (LH) leads to synthesis and

\footnotetext{
${ }^{1}$ All correspondence to: Sudipta Maitra. Department of Zoology, Visva-Bharati, Santiniketan 731235, India. Tel: +91 9874405555 or +91 8116978904. E-mail: smaitra3@gmail.com or sudipta.maitra@visva-bharati.ac.in

${ }^{2}$ Department of Zoology, Visva-Bharati, Santiniketan 731235, India

${ }^{3}$ Present address: Department of Genetics, The University of Texas, MD Anderson Cancer Center, Houston, Texas, USA
}

secretion of maturation-inducing steroid (MIS) in the ovary. $17 \alpha, 20 \beta$-Dihydroxy-4-pregnen-3-one (DHP) is the principal MIS in salmonids, cyprinids and many other teleost orders, but $17 \alpha, 20 \beta, 21$-trihydroxy4-pregnen-3-one (20ß-S) predominates in sciaenids and in marine perciform species (Nagahama, 1997). MIS action at the oocyte surface through membrane progestin receptor (mPR), a member of G-protein coupled receptor (GPCR), triggers the rapid activation of intra-oocyte signalling events as well as de novo synthesis of protein(s) from maternally stored mRNAs leading to the activation of maturation-promoting factor (MPF) (Zhu et al., 2003). Active MPF promotes the progression from meiotic MI-MII through histone 
H1 kinase activation, chromosome condensation, spindle formation, dissolution of nuclear envelope (germinal vesicle breakdown; GVBD) and release of the first polar body that ultimately converge to produce functional female gametes (Nagahama \& Yamashita, 2008). Although the nature of MIS, its cell surface-initiated action and its role in MPF activation is relatively ubiquitous, the molecular mechanisms underlying MIS action, more specifically recruitment of various intra-oocyte signalling events, varies considerably in fish and amphibian oocytes (KajiuraKobayashi et al., 2000; Nagahama \& Yamashita, 2008).

High intra-oocyte cAMP congruent with elevated cAMP-dependent protein kinase (PKA) activity is widely held responsible for the maintenance of prophase I arrest in teleosts (Das et al., 2017 for review). Studies in Atlantic croaker, zebrafish and goldfish indicated that MIS action at the oocyte surface involved the participation of pertussis toxin-sensitive inhibitory G-protein $\left(\mathrm{G}_{\mathrm{i}}\right)$, the downregulation of adenylyl cyclase (AC) activity and a decrease in intra-oocyte cAMP levels (Yoshikuni \& Nagahama, 1994; Zhu et al., 2003; Pace \& Thomas, 2005a, Thomas, 2012; Das et al., 2017). Insulin stimulation of meiotic maturation in zebrafish oocytes involves the downregulation of PKA activity, possibly through the PI3K/Akt/PDE3 pathway and high cAMP/PKA could successfully block meiosis resumption due to receptor tyrosine kinase (RTK) activation (Das et al., 2013; Maitra et al., 2014). Conversely, in Atlantic croaker, 20ß-S (the natural MIS)-induced oocyte maturation involves a significant decrease in cAMP production, however PKA inhibitors failed to induce meiosis (Pace \& Thomas, 2005b). Collectively, these data indicated that species-specific variations exist in upstream signalling events that participate in PKA inhibition leading to meiotic G2-M1 transition in teleost oocytes. Although the involvement of high AC activity in maintaining prophase arrest is ubiquitous in fish oocytes, it is not yet clearly understood if the high level of cAMP/PKA is maintained solely by the AC pathway or some other signalling is also involved in this process.

In addition to AC-mediated signalling cascades, MIS-induced oocyte maturation events in starfish (Okumura et al., 2002), Atlantic croaker (Pace \& Thomas, 2005b) and Indian shad (Pramanick et al., 2014) have been shown to depend on cAMP-independent phosphatidylinositol 3-kinase (PI3K)/protein kinase B (PKB, also known as Akt). Furthermore, the activation of the PI3K/Akt pathway is essential for insulin/IGF1-stimulated oocyte maturation in Xenopus and zebrafish (Andersen et al., 2003; Das et al., 2013). While full activation of Akt requires dual phosphorylation on Thr308 and Ser473 by phosphatidylinositoldependent kinase (PDK1) and the rictor-mTOR complex respectively (for review see Manning \& Cantley, 2007), membrane recruitment of Akt and PDK1, both containing pleckstrin homology domain, is mediated by phosphatidylinositol 3-phosphate (PIP3), a phospholipid second messenger produced by the action of PI3K. The family of PI3Ks is comprised of 14 enzymes that are separated into three classes, out of which class IB PI3Ks are activated by binding to free $\beta \gamma$ subunits of heterotrimeric G-protein (Stephens et al., 1997; Murga et al., 1998; Manning \& Cantley, 2007).

Mitogen-activated protein kinases (MAPK3/1, or extracellular signal-regulated kinases, ERK1/2) are rapidly activated in response to various growth factors and hormones including steroids. This signalling cascade family is regulated by upstream kinases including Mos and/or Raf and MEK (Pearson et al., 2001). While Ras-dependent activation of Raf is non-genomic, several earlier studies have demonstrated that Mos/MAPK is activated almost universally during meiotic G2-M1 transition (Ferrell, 1999; Liang et al., 2007). Further, GPCR-mediated ERK phosphorylation can be regulated by $G \beta \gamma$ via the recruitment of small G-protein Ras to the plasma membrane leading to ERK activation through the Raf/MEK/ERK pathway (Crespo et al., 1994). Although its role as a component of cytostatic factor to suppress DNA replication between meiosis I and II is ubiquitous; the need for MAPK activation for GVBD is uncertain and species-specific in fish and amphibian models (Ferrell, 1999; Kajiura-Kobayashi et al., 2000; Liang et al., 2007, Khan \& Maitra, 2013).

Zebrafish provides an excellent model for the study of ovarian growth, development, steroidogenesis, oocyte maturation and ovulation (Ge, 2005; Das et al., $2016 a, b)$. DHP has been shown previously to be the principal MIS in this species (Selman et al., 1994; Kondo et al., 1997). Significant progress has been made towards the identification and characterization of the membrane MIS receptors $(\mathrm{mPR} \alpha$ and $\mathrm{mPR} \beta)$ in zebrafish (Zhu et al., 2003; Hanna et al., 2006; Hanna $\& \mathrm{Zhu}, 2011)$. We have previously demonstrated the involvement of the PI3K/Akt signalling pathway in insulin-induced MPF activation in this species (Das et al., 2013). In addition, the role of elevated cAMP has been shown to inhibit insulin action on the oocyte GVBD response (Maitra et al., 2014). However, relatively less information is available on the participation and potential interaction between rapid non-genomic signalling events during meiotic G2-M1 transition under the influence of MIS in this species. Accordingly, the primary objective of the present investigation was to study the potential involvement of PI3K-Akt and MEK-MAPK cascades, either alone or in combination, in the regulation of PKA activity and GVBD response in DHP-treated zebrafish oocytes. 


\section{Materials and Methods}

\section{Animal collection and maintenance}

Adult zebrafish (Danio rerio), purchased from local pet stores in and around Santiniketan (Lat. $23^{\circ} 41^{\prime} 30^{\prime \prime} \mathrm{N}$, Long. $87^{\circ} 30^{\prime} 47^{\prime \prime} \mathrm{E}$ ), India, were maintained in 60 litre glass aquaria, under a $28 \pm 1^{\circ} \mathrm{C}$ and $14 \mathrm{~h}$ light: $10 \mathrm{~h}$ darkness cycle with lights turned on at $0600 \mathrm{~h}$. Fish were fed thrice daily with live blood worms and were acclimatized to laboratory conditions for at least 7 days before their use in experiments (Das et al., 2013). All animal experiments were carried out following the guidelines of the Institutional Animal Ethics Committee of Visva-Bharati University and approved by the committee according to Indian law.

\section{Chemicals and antibody}

Rabbit polyclonal anti-Akt:sc-8312, anti-p-Akt (Ser 473):sc-7985-R, anti-ERK1:sc-93, anti-p-ERK1/2 (Thr 202/Tyr204):sc-16982, anti-PKA $\alpha$ cat:sc-903 and antip-PKA $\alpha / \beta / \gamma$ cat:sc-32968 antibodies were obtained from Santa Cruz Biotechnology (Santa Cruz, CA, USA). Antibodies used in the present study have been reported previously to cross-react specifically with zebrafish proteins (Das et al., 2013; Maitra et al., 2014). Unless otherwise specified, hormones, inhibitors, antiRabbit IgG and other reagents were from SigmaAldrich, India.

\section{Oocyte preparation and in vitro culture}

For all in vitro experiments, zebrafish were autopsied in the evening $(2000 \mathrm{~h})$ when a lower percentage of oocytes matures spontaneously in the absence of exogenous stimuli (Hanna \& Zhu, 2011). Gravid females $(n \sim 30-40)$ were anesthetized by brief cold shock, decapitated, ovaries excised aseptically and placed immediately in oxygenated zebrafish Ringer (116 mM NaCl, $2.9 \mathrm{mM} \mathrm{KCl}, 1.8 \mathrm{mM} \mathrm{CaCl}_{2}$, $5 \mathrm{mM}$ HEPES; $\mathrm{pH}$ 7.2) supplemented with penicillin $(100 \mathrm{IU} / \mathrm{ml})$ and streptomycin $(100 \mathrm{mg} / \mathrm{ml})$ (Kondo et al., 1997). This preparation was also used as incubation medium in subsequent in vitro experiments. The protocol for harvesting post-vitellogenic intact follicles, enzymatic removal of the follicular layer, selection of oocytes divested of surrounding follicular cells and with centrally placed germinal vesicle $(\mathrm{GV})$ were according to our standard laboratory protocols and have been described earlier (Das et al., 2013, 2016a). In brief, ovarian follicles were incubated in $\mathrm{Ca}^{2+}$-free zebrafish Ringer's solution containing $0.001 \%$ collagenase type-IA $(1.25 \mathrm{U} / \mathrm{ml})$ for $1 \mathrm{~h}$ at $20 \pm 1{ }^{\circ} \mathrm{C}$ with mild agitation. Follicular cells were removed by repeated $(30 \times)$ gentle pipetting through a narrow pipette $(1 \mathrm{~mm}$ diameter) at $10 \mathrm{~min}$ intervals during incubation. Oocytes that showed signs of damage or the presence of fibrous amorphous follicle cells (incomplete denudation) were discarded manually. Complete removal of the follicular cells was ascertained by the absence of DAPI-positive nuclei surrounding the denuded oocytes (Das et al., 2013), and were unresponsive to meiotic maturation due to hCG stimulation (Das et al., 2013). Healthy, denuded oocytes of desired sizes (mean diameter $\sim 550-600 \mu \mathrm{m}$ ) were washed thoroughly with fresh zebrafish Ringer solution and were cultured in a 24-well tissue culture plate (50-60 oocytes/well) for the indicated time in hours and at $25 \pm 1^{\circ} \mathrm{C}$ under gentle agitation. AC activator forskolin (FK, $5 \mu \mathrm{M}$ ) that specifically raised the intra-cellular cAMP level, PI3K inhibitor wortmannin (Wrt, $10 \mu \mathrm{M})$, LY294002 (LY, $25 \mu \mathrm{M})$, and MEK1/2 inhibitor U0126 $(10 \mu \mathrm{M})$ were dissolved in DMSO. DHP was dissolved in ethanol. Cell-permeable, chemically stable cAMP analogue, dibutyryl (db) cAMP (1 mM) that increases intracellular cAMP level were dissolved in nuclease free water (Fermentas) just before the experiment. Inhibitors were added to the culture medium $2 \mathrm{~h}$ prior to DHP (5 nM) addition. The doses of DHP, LY294002, forskolin and db-cAMP used were as described earlier in this fish species (Das et al., 2013, 2016a; Maitra et al., 2014). Selection of the most effective dose of wortmannin and U0126 to block Akt and ERK1/2 phosphorylations as well as cross-specificity of each inhibitor were checked through immunoblot analysis. All chemicals were prepared at 1000 -fold stock and oocytes in control wells received equivalent amount of solvent $(1 \mu \mathrm{l} /$ well $)$ only. GVBD was monitored at indicated time intervals following immersion in clearing solution (ethanol: formaldehyde: acetic acid, 3: 6: $1 \mathrm{v} / \mathrm{v}$ ) under an inverted microscope (Victory FL, Dewinter Optical Inc.) and processed for preparation of oocyte extract and immunoblot analysis.

\section{Preparation of oocyte extract}

Samples were harvested at appropriate time intervals, washed $(3 \times)$ and homogenised in chilled oocyte extraction buffer containing $100 \mathrm{mM}$ sodium $\beta$-glycerophosphate, $20 \mathrm{mM}$ HEPES, $15 \mathrm{mM} \mathrm{MgCl}$, $5 \mathrm{mM}$ EGTA, $100 \mu \mathrm{M}$ p-PMSF, $3 \mu \mathrm{g} / \mathrm{ml}$ leupeptin, $1 \mathrm{mM}$ DTT and $1 \mu \mathrm{g} / \mathrm{ml}$ aprotinin; $\mathrm{pH}$ 7.5. Supernatant was separated by spinning the samples at $17,500 \mathrm{~g}$ for $20 \mathrm{~min}$ at $4^{\circ} \mathrm{C}$ and was either used immediately or stored at $-86^{\circ} \mathrm{C}$ until further use. As activation of MAPK cascade potentially involves interaction with large scaffolding complexes (Raman et al., 2007), whole homogenates, supernatants and pellet fractions were prepared and tested for relative protein content (Methods S1). 


\section{Electrophoresis and immunoblot analysis}

Oocyte lysates ( $\mu$ g protein; Lowry et al., 1951) from indicated treatment groups were subjected to SDSPAGE and immunoblot analysis according to our standard laboratory protocols as described earlier (Das et al., 2013; Maitra et al., 2014). In brief, $40 \mu \mathrm{g}$ of oocyte lysates were mixed with $2 \times$ SDS sample buffer (125 mM Tris- $\mathrm{HCl} \mathrm{pH}$ 6.8, 4\% SDS, 20\% glycerol, $10 \%$ 2-mercaptoethanol, $0.002 \%$ bromophenol blue) at a ratio of $1: 1$, boiled for $5 \mathrm{~min}$, cooled at room temperature and then resolved in 15\% SDS-PAGE. After the transfer of proteins, the Hybond-P PVDF membrane (GE Healthcare Biosciences, UK) were blocked in 5\% BSA in TBST ( $50 \mathrm{mM}$ Tris, $150 \mathrm{mM} \mathrm{NaCl}$, $0.1 \%$ Tween-20, $\mathrm{pH} 7.6$ ), overnight at $4^{\circ} \mathrm{C}$ followed by primary antibody (1:500 in blocking buffer) and alkaline phosphatase tagged anti-rabbit IgG (1:1000) for 4 and $2 \mathrm{~h}$ respectively at room temperature. Bands were developed by adding BCIP-NBT, recorded in Gel Doc apparatus (Bio-Rad) and imported into Adobe Photoshop. Band intensities were quantified by ImageJ software and expressed as arbitrary units (AU).

\section{Histone H1 kinase assay}

Histone H1 kinase activation, a reliable marker for p34cdc2 activation, was assayed as described earlier (Das et al., 2013). In brief, $20 \mu \mathrm{l}$ of oocyte lysate (100 $\mu \mathrm{g}$ protein) from each treatment group were incubated at $30^{\circ} \mathrm{C}$ for $2 \mathrm{~min}$ in the presence of $100 \mu \mathrm{M}$ histone H1 (Type-III-S); $500 \mu \mathrm{M}$ ATP; $1.5 \mu \mathrm{Ci} \gamma^{32} \mathrm{P}$-ATP (3500 $\mathrm{Ci} / \mathrm{mmol}$; Board of Radiation and Isotope Technology, Department of Atomic Energy, Govt. of India); $1 \mathrm{mM}$ EGTA, $10 \mathrm{mM} \mathrm{MgCl2;} 4.5 \mathrm{mM}$ 2-mercaptoethanol and $20 \mathrm{mM}$ Tris- $\mathrm{HCl}$ ( $\mathrm{pH}$ 7.4). The kinase reaction was stopped by adding $20 \mu \mathrm{l}$ of $300 \mathrm{mM}$ phosphoric acid and $80 \mu \mathrm{l}$ of reaction mixture was spotted on Whatman P81 phosphocellulose paper (Whatman, Brentford, UK), washed three times with $1 \%$ phosphoric acid, dried, and radioactivity was measured in a liquid scintillation counter (Perkin Elmer). For determination of histone $\mathrm{H} 1$ phosphorylation by autoradiography, the reaction was stopped by adding $40 \mu \mathrm{l}$ of $2 \times$ SDS sample buffer. Samples were heated at $95^{\circ} \mathrm{C}$ for $5 \mathrm{~min}$ and then resolved on 15\% SDS-PAGE, along with pre-stained molecular weight marker proteins (Fermentas). The band corresponding to histone H1 was gel excised and transferred to PVDF membrane and recorded in a Storm 860 phosphoimager. Data were analyzed using Quantity One image software (GE Healthcare Biosciences).

\section{Data analysis}

All values were mean \pm standard error of the mean (SEM) of at least three independent observations using oocytes from different donor fish $(n \geq 5)$. Data were analyzed by one-way analysis of variance (ANOVA), followed by Duncan's multiple range test for multiple group comparisons, a $P$-value $<0.05$ was considered to be statistically significant.

\section{Results}

\section{DHP stimulation of Akt and MAPK (ERK1/2) phosphorylation in maturing zebrafish oocyte}

Kinetics of Akt and ERK1/2 phosphorylation was determined by immunoblot analysis using anti-pAkt (Ser473) and anti-p-ERK1/2 (Thr202/Tyr204) antibody respectively that specifically recognize the phosphorylated (active) form of these proteins. Although total protein did not vary significantly, DHP stimulation of denuded zebrafish oocytes could promote rapid phosphorylation of Akt (Fig. 1A) and ERK1/2 (Fig. 1B) as early as 15 min of incubation in vitro. While p-Akt (Ser473) reached its peak between 60 to $90 \mathrm{~min}$ and came to the basal level by $120 \mathrm{~min}$ (Fig. 1A); p-ERK1/2 increased significantly $(P<0.05)$ at $2 \mathrm{~h}$ of DHP stimulation and remained high afterwards (until 4 h) (Fig. 1B). Moreover, the kinetics of histone $\mathrm{H} 1$ kinase activation, a reliable marker for p34cdc2 kinase activity (MPF activation), underwent a sharp increase between 3 to $5 \mathrm{~h}$ of steroid stimulation (Fig. 1C) and revealed a tight temporal relationship with elevated GVBD response (Fig. 1C).

\section{Selection of doses and testing cross-reactivity for PI3K and MEK1/2 inhibitors and their effect on the GVBD response}

As both Akt and ERK phosphorylation were detected as early as after $15 \mathrm{~min}$ of incubation, i.e. much earlier than the highest GVBD response at $5 \mathrm{~h}$, the need for these pathways during meiosis resumption was investigated. Doses for wortmannin and U0126 were selected using western blot analysis for their ability to block Akt and ERK1/2 phosphorylations respectively. As shown in Fig. 2, although the total protein did not vary significantly, maximum inhibition of Akt and ERK1/2 phosphorylation was found with a $10 \mu \mathrm{M}$ dose for both the inhibitors at the respective time points tested (Fig. 2A, B). Furthermore, the crossspecificity of the selected doses of the inhibitors was also checked. As shown in Fig. 2(C,D), no changes in band intensities were observed due to the selected doses of wortmannin $(10 \mu \mathrm{M})$ and U0126 $(10 \mu \mathrm{M})$ on DHP-induced p-ERK1/2 and p-Akt immunoblot respectively. Moreover, denuded oocytes were preincubated with two different PI3K inhibitors, either wortmannin (Wrt, $10 \mu \mathrm{M}$ ) or LY294002 (LY, $25 \mu \mathrm{M}$ ) as 
A)

B)

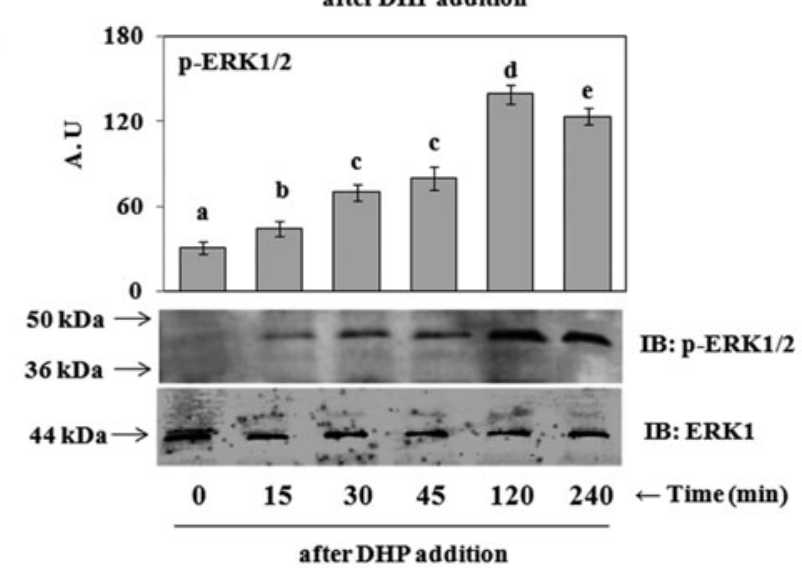

C)

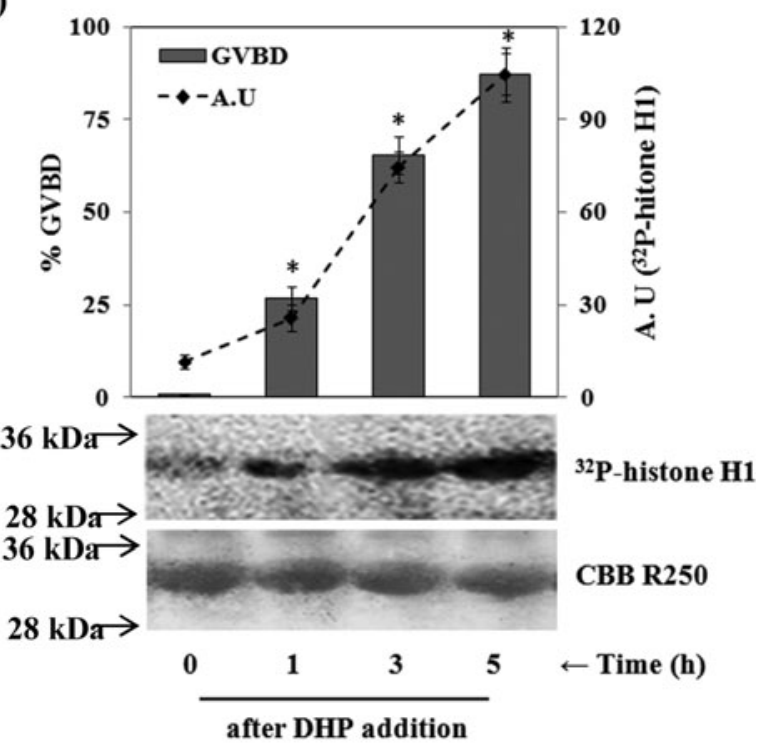

Figure 1 MIS stimulation of Akt and ERK1/2 phosphorylation for germinal vesicle breakdown (GVBD) and histone-H1 kinase activation in zebrafish oocyte in vitro. Denuded oocytes were treated with DHP $(5 \mathrm{nM})$ and oocyte lysates from the indicated time intervals were analyzed by SDS-PAGE followed by immunoblot analysis (lower panels) using either anti-pAkt (Ser473) $(A)$ or anti-p-ERK1/2 antibody $(B)$ that specifically recognizes the activated form of the protein or assayed for histone-H1 kinase activation, a reliable marker of MPF activation by autoradiography along with GVBD response (C). AntiAkt or anti-ERK1 immunoblot, or Coomassie brilliant blue R-250 (CBB R250) staining served as the internal loading control. The corresponding densitometric analysis were also given in arbitrary units (AU, upper panels). The percentage of GVBD was scored microscopically. Values are mean \pm standard error of the mean (SEM) of three independent experiments. Data were analyzed by one-way ANOVA $(P<0.001)$ and Duncan's multiple range test $(P<0.05) .{ }^{a-e}$ Groups with the same lowercase letters above the bars are not significantly different and those with different letters differ significantly $(P<0.05)$. Immunoblot data are representative of at least three independent experiments that showed identical results.

well as pharmacological MEK inhibitor, U0126 $(10 \mu \mathrm{M})$ for $2 \mathrm{~h}$ followed by DHP stimulation. While prior inhibition of PI3K/Akt signalling delayed the GVBD response markedly up to $3 \mathrm{~h}$ of incubation, MEK1/2 inhibitor could neither block nor delay MIS-induced oocyte maturation significantly (Fig. 2E). Conversely, the simultaneous inhibition of PI3K/Akt and MEKMAPK pathways could successfully reverse DHPstimulated meiotic maturation at all the time points tested (Fig. 2E).

\section{Inhibition of PI3K and MEK1/2 reverse DHP-mediated inactivation of PKA}

MIS stimulation of resumption of meiotic maturation involves the activation of inhibitory G-protein $\left(\mathrm{G} \alpha_{\mathrm{i}}\right)$, allowing a transient decrease in intra-oocyte cAMP levels in zebrafish and other fish models (Zhu et al., 2003; Pace \& Thomas, 2005a). Accordingly, in the present study, PKA involvement was examined during the DHP-induced GVBD response by immunoblot analysis using $\mathrm{p}-\mathrm{PKA} \alpha / \beta / \gamma$ cat (Thr198) antibody. Phosphorylation of the PKA catalytic subunit (PKAc) has been shown to correlate well with its catalytic activity, as PKAc is always phosphorylated on the activation loop allowing proper substrate recognition and catalysis (Moore et al., 2002; Khan \& Maitra, 2013; Maitra et al., 2014). Time kinetics data revealed that although total protein (PKAc) did not vary significantly, DHP stimulation could attenuate p-PKAc significantly $(P<0.05)$ as early as after $30 \mathrm{~min}$ of incubation (lane 2, Fig. $3 A$ ) that progressed further to 
A)

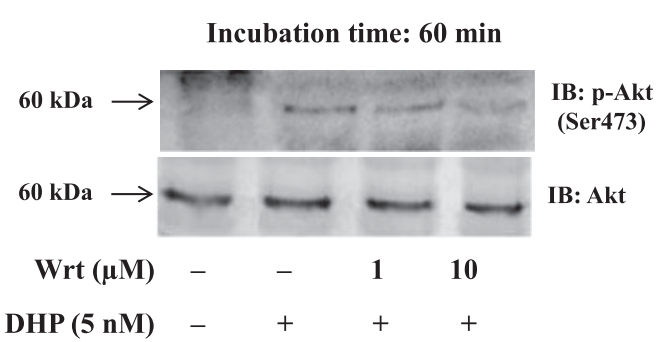

C)

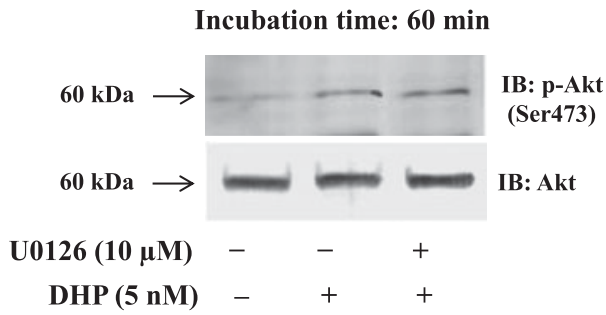

B)

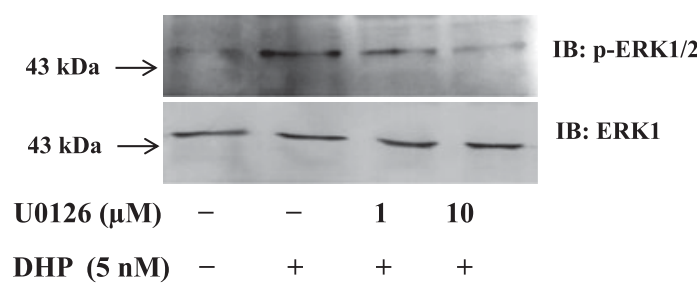

D)

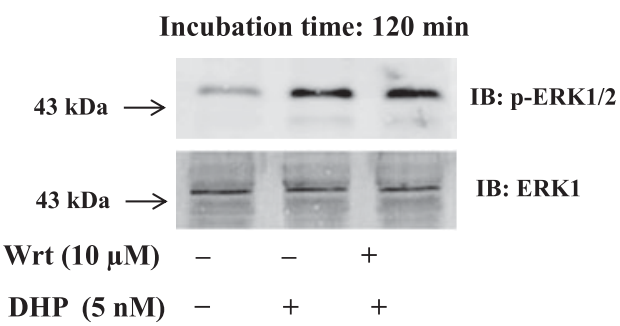

Figure 2 Effect of PI3K and MEK1/2 inhibition, either alone or in combination, on meiotic G2-M1 transition in vitro. To determine the highest effective doses of PI3K and MEK1/2 inhibitors and their cross-specificity, fully grown immature defolliculated oocytes were primed without (Con) or with increasing concentration of wortmannin (Wrt; $1,10 \mu \mathrm{M})$ and U0126 $(1,10 \mu \mathrm{M})$, followed by DHP stimulation $(5 \mathrm{nM})$. Oocyte lysates from indicated time intervals were subjected to immunoblot analysis using anti-p-Akt (Ser473) and anti-p-ERK1/2 antibodies. Akt and ERK1 immunoblots served as the endogenous loading control. Furthermore, denuded oocytes were incubated without (Con) or with either wortmannin (Wrt, $10 \mu \mathrm{M})$ or LY294002 (LY, $25 \mu \mathrm{M})$ or U0126 $(10 \mu \mathrm{M})$ or Wrt/LY + U0126 for $2 \mathrm{~h}$ followed by DHP $(5 \mathrm{nM})$ stimulation; GVBD was scored microscopically. Data are representative of at least five independent experiments from separate fish showing identical results. Values are the mean \pm standard error of the mean (SEM) of three independent experiments and data were analyzed by oneway analysis of variance (ANOVA) $(P<0.001)$ and Duncan's multiple range test $(P<0.05)$. Mean values with different superscripts, small letters, capital letters and numbers $(\mathrm{a}, \mathrm{b}, \mathrm{A}-\mathrm{C}, 1,2)$ indicate significant differences among different time groups (i.e. $1 \mathrm{~h}, 3 \mathrm{~h}$ and $5 \mathrm{~h}$ respectively).

reach the basal level at $120 \mathrm{~min}$ of incubation in vitro (lane 4, Fig. 3A). Next, the potential involvement of PI3K/Akt and MEK/MAPK pathways, either alone or in combination, on PKA phosphorylation (activation) was examined. While high levels of p-PKAc, signifying elevated PKA activity in G2-arrested oocytes, underwent a sharp decrease in the DHP-treated group (lanes 1 and 2, Fig. 3B), priming with wortmannin could partially reverse DHP action on p-PKAc dephosphorylation (lane 3, Fig. 3B). In contrast, although pre-incubation with U0126 was largely without effect (lane 4, Fig. 3B), the simultaneous inhibition of MEK and PI3K function could abrogate DHP-mediated $\mathrm{p}$ PKAc dephosphorylation (lane 5, Fig. 3B), indicating PI3K/Akt and MEK/MAPK signalling cascades, together but not alone, might have a pivotal influence in PKA deactivation in DHP-induced zebrafish oocytes allowing the resumption of meiotic maturation in vitro.

\section{Effect of high intra-oocyte cAMP on DHP-induced Akt and ERK1/2 phosphorylations}

To determine the possibility of any cross-talk between major signalling cascades, next we examined the effect of high cAMP on steroid-stimulated Akt and MAPK phosphorylation. Denuded oocytes were preincubated with AC activator forskolin and cellpermeable db-cAMP, both of which are known to elevate intra-cellular cAMP levels and have been used earlier in this fish species (Maitra et al., 2014). While total protein (Akt and ERK1) remained unchanged, elevated intra-oocyte cAMP levels could successfully attenuate DHP-stimulated Akt (Ser473) and ERK1/2 phosphorylation (Fig. 4A) as well as histone H1kinase activity (Fig. $4 B$ ) suggesting, congruent with elevated p34cdc2 activity, that elevated Akt and MAPK phosphorylation (activation) levels are sensitive to high levels of cAMP.

\section{Discussion}

Data from the present study demonstrated that DHP stimulation of zebrafish oocytes in vitro induced phosphorylation of Akt (Ser473) as early as after $15 \mathrm{~min}$ incubation. While the kinetics of histone H1 kinase activation showed a tight temporal relationship with the GVBD response between 1-5 $\mathrm{h}$ of MIS 

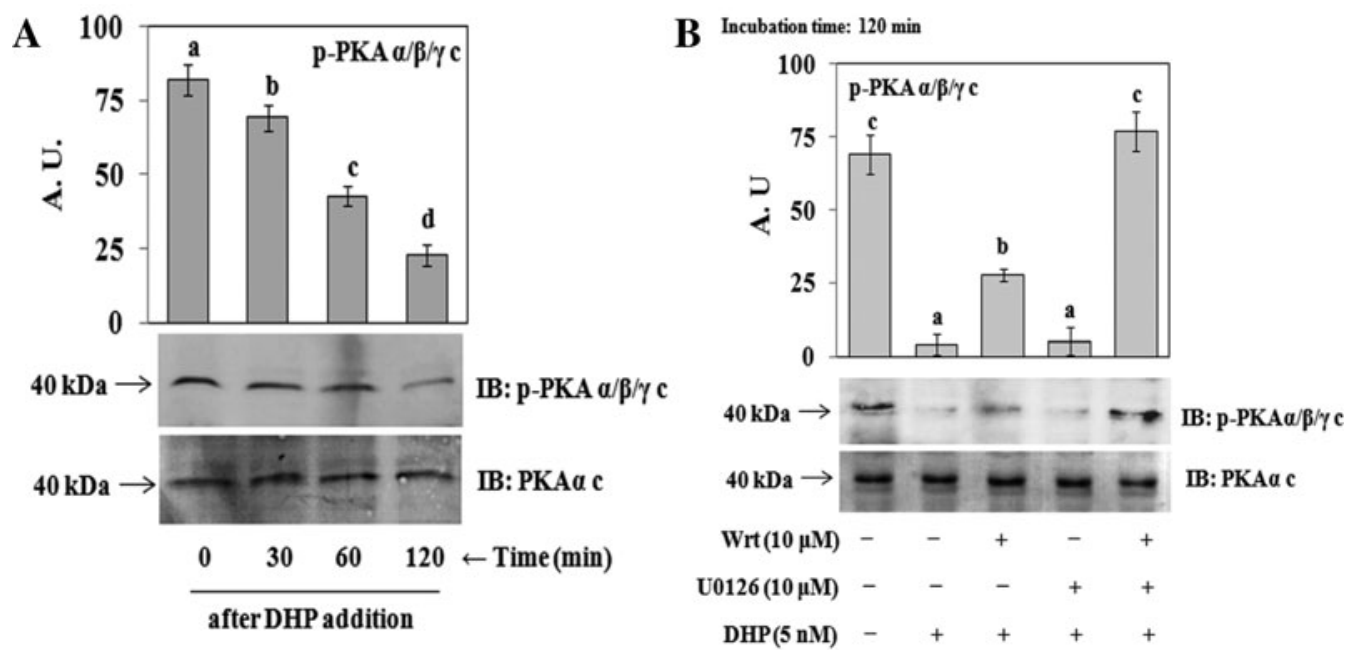

Figure 3 Kinetics of steroid-induced p-PKAc dephosphorylation (inhibition) $(A)$ and effect of priming with PI3K and/or MEK1/2 inhibitors on DHP-induced p-PKAc dephosphorylation $(B)$. Defolliculated oocytes were either stimulated with DHP $(5 \mathrm{nM})$ alone or were primed $(2 \mathrm{~h})$ with wortmannin $(\mathrm{Wrt}, 10 \mu \mathrm{M})$ and U0126 $(10 \mu \mathrm{M})$ followed by DHP $(5 \mathrm{nM})$ stimulation for indicated time intervals. Oocyte lysates were analysed by SDS-PAGE and subjected to immunoblot analysis using anti-pPKA $\alpha / \beta / \gamma$ cat antibody. Anti-PKA $\alpha \mathrm{c}$ immunoblot served as internal loading control. Corresponding densitometric analysis were also given. Values are mean \pm standard error of the mean (SEM) of three independent experiments. Data are analyzed by one-way ANOVA followed by Duncan's multiple range test. ${ }^{\mathrm{a}-\mathrm{d}}$ Groups with same lowercase letters above the bars are not significantly different and those with different letters differ significantly $(P<0.05)$. Immunoblot data are representative of at least three independent experiments from separate fish showing identical results.

stimulation, p-Akt (Ser473) reached its peak much earlier, i.e. during 60 to $90 \mathrm{~min}$ of DHP stimulation in vitro. Previously, stimulation with MIS (20ß-S) has been shown to promote phosphorylation of Akt in Atlantic croaker oocyte (Pace \& Thomas, 2005b). In starfish oocyte, Akt is phosphorylated within a few minutes of 1-methyladenine addition; microinjection of constitutively active Akt mRNA could induce meiosis in the absence of 1-methyladenine, the natural MIS in this species (Okumura et al., 2002). Moreover, in mouse cumulus-free oocytes, p-Akt has been detected at $20 \mathrm{~min}$ and Akt phosphorylation precedes onset of GVBD both in vivo and in vitro (Kalous et al., 2006). The available information indicates that insulin/IGF1 stimulation of meiotic G2-M1 transition in zebrafish and Xenopus oocytes involves Akt activation (Andersen et al., 2003; Das et al., 2013). Although growth-factormediated Akt activation requires RTK activation, in oocytes MIS regulation of Akt phosphorylation (activation) may primarily involve the activation of GPCR (Sadler \& Ruderman, 1998; Pace \& Thomas, 2005b). Earlier evidence has established that rapid, non-genomic activation of Akt could be triggered through G $\beta \gamma$ subunits of heterotrimeric G-protein that might dissociate upon ligand binding to membrane GPCR followed by the activation of class 1B PI3K (Stephens et al., 1997; Murga et al., 1998).

Data from the present study demonstrated that DHP-induced meiotic maturation in zebrafish oocytes involves the early activation of MAPK3/1 (ERK1/2), an event initiated within $15 \mathrm{~min}$ (i.e. much earlier than MPF activation), progresses up to $120 \mathrm{~min}$ and remains high thereafter. Rapid activation of ERK1/2 through a non-genomic pathway has been shown earlier in zebrafish $\mathrm{mPR} \alpha / \mathrm{mPR} \beta$ transfected cells (Hanna et al., 2006). Although the need for ERK activation prior to meiosis resumption in teleost is highly debated, available information indicates that ERK activation is almost universal during oocyte maturation (Ferrell, 1999). While it is activated before GVBD in equine, porcine and bovine oocytes, in rat and mouse ERK is activated after MPF activation and GVBD (Liang et al., 2007) suggesting species-specific differences exist for the time kinetics of ERK activation during G2-M1 transition. In addition, progesterone stimulation induces the synthesis of maternally stored mos mRNA that activate MEK/ERK pathway and the overexpression of Mos or constitutively active ERK2 is enough to resume meiosis even in the absence of steroid stimulation in Xenopus (Sagata et al., 1989; Posada et al., 1993).

The present results show that pharmacological inhibition of PI3K/Akt pathway delays the DHPinduced (5 $\mathrm{nM})$ GVBD response in zebrafish oocytes for the first $4 \mathrm{~h}$ of incubation and are in agreement with our earlier observation with low level of DHP (3 nM) stimulation in this species (Das et al., 2016a). Conversely, PI3K/Akt activation is apparently 
A)

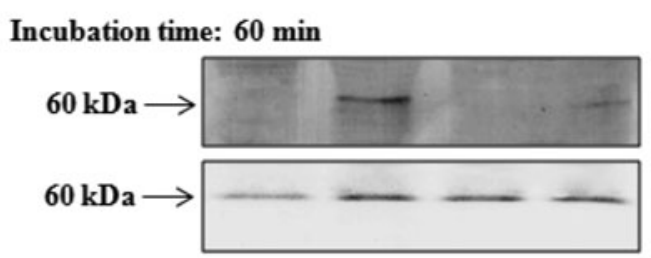

IB: p-Akt (Ser473)

IB: Akt

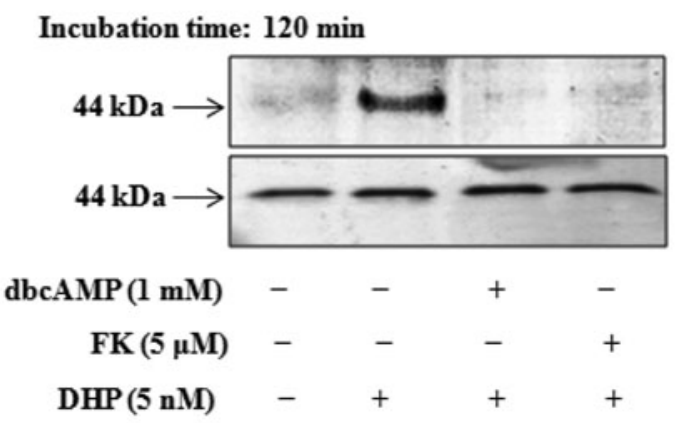

IB: p-ERK1/2

IB: ERK

B)

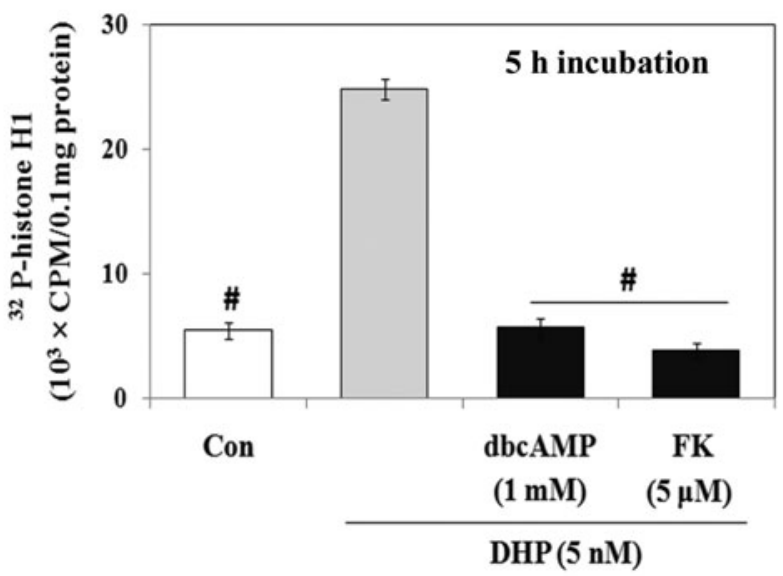

Figure 4 Effect of high cAMP on Akt and ERK1/2 phosphorylation $(A)$ and histone H1-kinase activation $(B)$. Defolliculated oocytes were either stimulated with DHP (5 nM) alone or were pre-incubated $(2 \mathrm{~h})$ with forskolin or db-cAMP followed by steroid stimulation. Oocyte lysates from various treatment groups were subjected to immunoblot analysis using anti-p-Akt (Ser473) or anti-p-ERK1/2 antibodies and assayed for histone H1 kinase activation by scintillation counting. Anti-Akt and anti-ERK1 (total protein) immunoblot served as internal loading control. Values are mean \pm standard error of the mean (SEM) of three independent experiments. Data are analyzed by one-way ANOVA followed by Duncan's multiple range test. \# $P<$ 0.001, compared with DHP-stimulated group. Immunoblot data are representative of at least three independent experiments from separate fish showing identical results.

indispensable for insulin-induced meiotic maturation in zebrafish, in which PDE3 might be a downstream target (Das et al., 2013). These observations suggest that although it is functionally important, activation of PI3K/Akt might have a differential role during growth factor-induced and steroid-induced meiosis resumption (Das et al., 2016a). However, the expression of a dominant negative PI3K (p85deltaSH2N) or overexpression of PI3K to inhibit or promote zebrafish oocyte maturation either in the presence or absence of MIS respectively, could provide strong evidence for an essential role for PI3K in the regulation of meiosis resumption in this species in the future. Interestingly, the present data conform with earlier reports in Xenopus, in which PI3K inhibition either delays (Bagowski et al., 2001) or is without effect on progesterone but not insulin/IGF1-stimulated meiotic maturation, suggesting that PI3K-mediated signalling acts as an auxiliary pathway for progesterone action (Andersen et al., 2003, Mood et al., 2004).

Furthermore, present data demonstrate that priming with MEK1/2 inhibitor, U0126 alone could neither block nor delay DHP-induced GVBD response in zebrafish oocytes. Earlier evidence has established 
that, in zebrafish oocytes, MEK inhibition in vitro could suppress insulin-stimulated meiotic maturation significantly, but not completely, and ERK1/2 activation by okadaic acid promotes the GVBD response suboptimally (Maitra et al., 2014). Although ERK activation is neither necessary nor sufficient for initiating meiosis in goldfish and Atlantic croaker oocytes (Kajiura-Kobayashi et al., 2000; Pace \& Thomas, 2005b), recent studies in perch oocyte have suggested that there is an involvement of ERK1/2 activation in PKA-inhibition-induced oocyte maturation (Khan \& Maitra, 2013). Furthermore, MEK inhibitor PD098059 inhibits follicular fluid-meiosis-activating-sterol (FFMAS)-induced GVBD but not spontaneous oocyte maturation in mouse (Faerge et al., 2001).

The present results show that pharmacological inhibition of MEK1/2 or PI3K/Akt together, but not alone, could successfully abrogate DHP-induced oocyte maturation in zebrafish oocytes in vitro. These data are in agreement with the earlier observation in Xenopus oocytes, in which attenuation of Mos/MEK function in addition to abrogating PI3K activity could effectively block the GVBD response induced by either high or low concentrations of progesterone. However, inhibition of any one pathway alone fails (Mood et al., 2004). Recently, we have reported that the PI3K/Akt pathway is indispensable for insulin-induced meiotic maturation in zebrafish, in which PDE3 might be a downstream target (Das et al., 2013). Inhibition of the PI3K/Akt pathway has been shown to abrogate 1-methyladenine-induced resumption of meiosis in starfish (Sadler \& Ruderman, 1998), 20ß-S-induced GVBD response in Atlantic croaker and striped bass (Weber \& Sullivan, 2001; Pace \& Thomas, 2005b), and DHP-induced oocyte maturation in Indian shad (Pramanick et al., 2014). Based on the above data it is reasonable to conclude that, while activation of either PI3K/Akt and MEK/MAPK signalling pathway may act in parallel to rescue MIS-induced GVBD response, simultaneous inhibition of these pathways might have a pivotal influence and may restrict the withdrawal of G2 (prophase I) arrest in zebrafish oocytes.

The available information indicates that high AMP level congruent with elevated PKA activity helps to maintain meiotic prophase I arrest in vertebrate oocytes and release from meiotic arrest accompanies AC inhibition, lowering of cAMP levels, and PKA inhibition (Conti et al., 2002; Nagahama \& Yamashita, 2008; Das et al., 2017). In Xenopus oocytes, during progesterone-stimulated oocyte maturation, the exact timing and extent of cAMP decrease and the necessity of PKA downregulation are still unclear and are characterised by conflicting reports (Daar et al., 1993; Schmitt \& Nebreda, 2002; Eyers et al., 2005; Nader et al., 2016). However, in zebrafish oocytes and also in zebrafish $\mathrm{mPR} \alpha / \beta$-transfected somatic cells, DHP stimulation promotes inhibitory G-protein $\left(\mathrm{G}_{\mathrm{i}}\right)$ allowing the downregulation of $\mathrm{AC}$ activity and a sharp fall in cAMP levels (Zhu et al., 2003; Hanna et al., 2006; Thomas, 2012). Data from the present study demonstrate that stimulation of zebrafish oocytes with DHP downregulates PKA activity (pPKAc dephosphorylation) within $30 \mathrm{~min}$ to $120 \mathrm{~min}$. Previously, we have shown that inhibition of either AC or PKA by pharmacological inhibitors alone is sufficient to promote a GVBD response even without hormonal stimulation in this species (Maitra et al., 2014; Das et al., 2016a). Furthermore, PKA inhibition alone has been found to remove meiotic arrest independent of MIS stimulation in various other teleosts (Haider \& Baqri, 2002; Khan \& Maitra, 2013; Hajra et al., 2016). Taken together these data indicate that downregulation of cAMP/PKA signalling in teleost oocytes plays a critical role in the process of MPF activation and the GVBD response.

In a recent study in Xenopus, it has been demonstrated that while lowering endogenous cAMP levels failed to induce spontaneous maturation, meiotic arrest could be released even in the presence of high levels of cAMP and resumption of meiosis is apparently insensitive to PKA inhibition (Nader et al., 2016). Earlier we have demonstrated that forced elevation of intra-oocyte cAMP prevents ERK1/2 phosphorylation as well as a GVBD response in zebrafish oocytes (Maitra et al., 2014; Das et al., 2016a). The present study shows that DHP downregulates PKA activation and pharmacological inhibition of PI3K and MEK function attenuates DHP-induced oocyte maturation. Therefore, it was important to check whether PI3K and MEK inhibitors could potentially interfere with MISinduced PKA inhibition (dephosphorylation). The present results revealed that although inhibition of MEK1/2 had been apparently without effect, blocking of PI3K could significantly reverse MIS action on p-PKAc dephosphorylation. Moreover, simultaneous inhibition of MEK-dependent and PI3K-dependent signalling could attenuate DHP-mediated p-PKAc dephosphorylation, suggesting that, unlike Xenopus, the downregulation of PKA activity is possibly an obligatory function during DHP-induced meiosis resumption in zebrafish oocytes. The involvement of the PI3K/Akt/PDE3 cascade in the downregulation of intra-oocyte cAMP level concomitant with PKA inactivation has been reported previously in fish and amphibian oocytes (Andersen et al., 2003; Pace and Thomas, 2005b; Das et al., 2013; Maitra et al., 2014). Moreover, the inhibition of PI3K has been shown to promote PKA activation that in turn successfully attenuates insulin-induced meiotic G2-M1 transition in catfish follicle enclosed oocytes in vitro (Hajra et al., 2016). Furthermore, studies in somatic cancer cells 

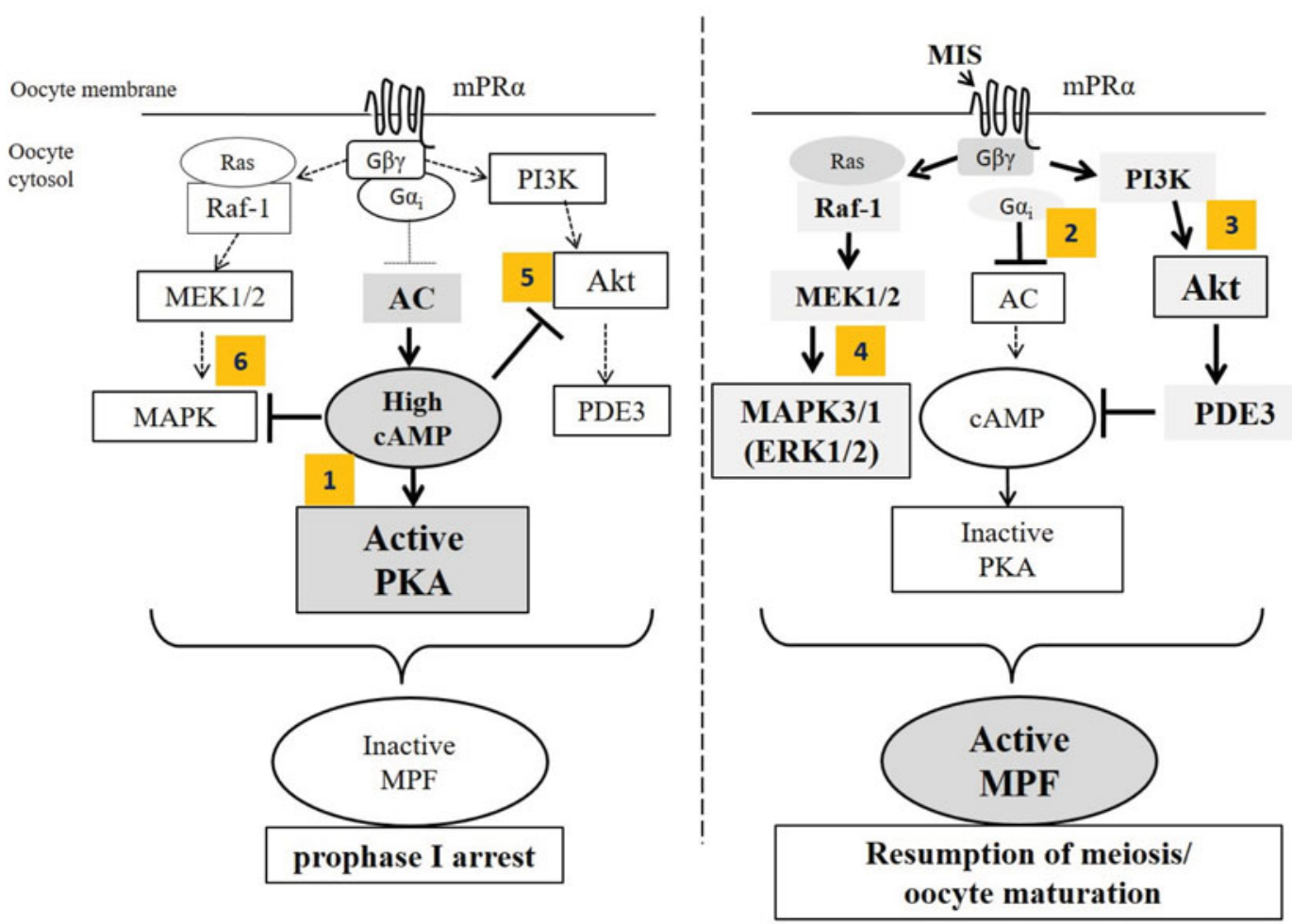

Figure 5 Proposed model for rapid activation of intra-oocyte signalling cascades in maturational steroid (DHP)-stimulated zebrafish oocytes and cross-talk between cAMP-mediated and PI3K/Akt- and MEK/MAPK-dependent signalling events. It is now well accepted that in the absence of MIS (left panel), high intra-oocyte cAMP/PKA inhibits MPF activation and resumption of meiosis (1). Conversely, it is documented that MIS action at the oocyte surface via its cognate G-protein coupled receptor (mPR) promotes activation of inhibitory G-protein (Gai), down-regulation of AC activity and cAMP level to promote meiosis (2). Interestingly, present data demonstrate that DHP stimulation triggers rapid phosphorylation of both Akt and ERK1/2 $(3,4)$ and forced elevation of intra-oocyte cAMP (through priming with Ac activator FK or non-degradable dbcAMP) attenuates both Akt and ERK1/2 phosphorylation/activation $(5,6)$. Rapid phosphorylation of Akt and MEK/MAPK in MIS treated cells, possibly involves release of G $\beta \gamma$ and rapid activation of PI3K $\gamma$ and Ras/Raf/MEK cascades respectively. Specifically, present results demonstrate that attenuation of MEK in combination with PI3K inhibition, but not alone, could abrogate DHP action on cAMP-dependent protein kinase (PKA) dephosphorylation (inhibition), hitherto considered as the major upstream regulator of MPF activation and meiotic G2-M1 transition.

have revealed that endogenous ribosomal S6-kinase (p-RSK), the substrate of ERK1/2, when remaining inactive, interacts with the PKA regulatory subunit (RI) thereby decreasing the interaction between RI and PKAc and leading to PKA activation (Chaturvedi et al., 2006; Gao \& Patel, 2009). Conversely, upon activation by ERK1/2, phosphorylated RSK1 blocks PKAc and decreases the ability of cAMP to activate the PKA holoenzyme (Chaturvedi et al., 2006; Gao \& Patel, 2009). Interestingly, it has been reported previously that RSK2, the major isoform in Xenopus oocytes, phosphorylates and inhibits Myt1. Myt1, in turn, phosphorylates and inactivates cdc2 (Palmer et al., 1998), while constitutively active RSK1 triggers meiotic G2-M1 transition (Gross et al., 2001). Clearly, in the future it would be interesting to examine whether potential synergism between PI3K/Akt and MEK1/2 in regulation of PDE3 activity along with inactive
RSK-mediated activation of PKA may ensure prophase arrest in zebrafish oocytes.

Next we examined the effect of high cAMP on the regulation of $\mathrm{p}$-Akt and $\mathrm{p}$-ERK in zebrafish oocytes undergoing meiotic G2-M1 transition due to MIS stimulation. Data from the present study demonstrated that prior elevation of intra-oocyte cAMP could successfully attenuate phosphorylation of Akt and MAPK, suggesting the possibility of a proximal interaction between these signalling pathways. In cultured human primary $\mathrm{T}$ lymphocytes, an increase in cAMP levels has been shown to inhibit PI3K/Akt and Ras-dependent activation of ERK1/2 that correlates well with the blockade of cell cycle progression (Grader-Beck et al., 2003). Furthermore, cAMP inhibits the synthesis of $\mathrm{p} 27 \mathrm{Kip} 1$ and cyclin D2 in rat C6 glioma cells and prevents $S$ phase entry by blocking Akt and ERK activities (Wang et al., 2001). Moreover, the 
ability of brain-derived neurotrophic factor (BDNF) to rescue cortical neurons from apoptosis after serum deprivation that required PI3K signal transduction cascade is attenuated by cAMP (Poser et al., 2003). Although further studies are required in the oocyte model, experimental evidence in cultured somatic cells suggests that high cAMP blocks the membrane localization of PDK1 and inhibits the lipid kinase activity of PI3K (Kim et al., 2001). Furthermore, thyroid stimulating hormone (TSH) inhibition of Akt activity via cAMP in PCCL3 cells suggests that a novel Epac-Rap1b-PP2A signalling module controls cAMPdependent Akt regulation (Lou et al., 2002; Hong et al., 2008). The attenuation of MIS-induced Akt activation by cAMP is reported here, however, for the first time in an oocyte model.

Moreover, cAMP inhibition of MAPK activation has been reported earlier in both normal and transformed cell types (Cook \& McCormick, 1993; Filardo et al., 2002; Funaki et al., 2010) as well as in oocytes (Sun et al., 1999; Lu et al., 2001; Maitra et al., 2014). Cross-talk between the cAMP and MAPK signalling pathways has been shown in COS and NIH3T3 cells, in which cAMP-dependent inhibition of the MAPK is mediated by Raf-1 (Dumaz \& Marais, 2003). PKA blocks Raf-1 activation by triggering inhibitory phosphorylation at Ser43, Ser233 and Ser259 residues, which allows binding of the 14-3-3 protein to Raf- 1 and prevents its binding to Ras-GTP (Gerits et al., 2008). Although high cAMP attenuation of c-Mos translation and MAPK activation cannot be ruled out during late stages of MIS stimulation (Sun et al., 1999; Lu et al., 2001), predominance of the phosphorylation cascade (through G $\beta \gamma$-Ras-RafMEK) is highly probable during rapid (within $15 \mathrm{~min}$ ) activation of MAPK (ERK1/2 phosphorylation) in zebrafish oocytes in vitro. Potential cross-talk between cAMP/PKA and membrane-initiated signalling axes in zebrafish oocytes has been reported previously and high intra-oocyte cAMP levels prevent insulininduced (RTK-mediated), as well as okadaic acidinduced, MAPK phosphorylation and oocyte GVBD (Maitra et al., 2014).

Although a pharmacological approach has its own level of limitations, the use of specific kinase inhibitors forms the main stay behind targeted therapy in cellcycle regulation in the clinical set up and is widely prevalent in the treatment of cancer patients in recent times. As far as we know, the present study shows for the first time the involvement and potential crosstalk between PI3K/Akt or MEK/MAPK pathways to promote MIS-induced PKA dephosphorylation and oocyte maturation through the use of specific pharmacological inhibitors. Regardless, further indepth studies involving the expression of a dominant negative PI3K (p858SH2N) to inhibit MIS action and/or overexpression of PI3K to promote oocyte maturation independent of steroid stimulation would provide strong evidence to reach a robust conclusion in future. Collectively our results indicate that, in the absence of maturational steroid, high intraoocyte cAMP/PKA potentially blocks MPF activation (Fig. 5, left panel). Conversely, DHP stimulation inhibits the cAMP/PKA-mediated signalling pathway, and triggers PI3K/Akt and MEK/MAPK signalling pathways to induce maturation (Fig. 5 , right panel). Therefore, the present data strengthen the view that PI3K/Akt, MEK/MAPK and cAMP/PKA-mediated signalling pathways may not be mutually exclusive and potentially forming a triad, components of which are selectively accessible to diverse stimuli (endocrine and/or autocrine/paracrine) and influence meiotic cell cycle progression.

\section{Statement of interest}

None

\section{Funding}

This work was supported by the DST-INSPIRE Program, Department of Science and Technology, New Delhi, India which provided a fellowship to D.D. Financial assistance was given from the UGC CAS program to the Department of Zoology, Visva-Bharati, Santiniketan, India.

\section{Acknowledgements}

The authors are grateful to Prof. S. Bhattacharya (Department of Zoology, Visva-Bharati, Santiniketan, India) for his generous gift of p-Akt (sc-7985-R) and Akt (sc-8312) antibodies. The authors are also thankful to the Head, Department of Zoology, VisvaBharati University, Santiniketan for providing the departmental facilities required for this investigation. The authors express their thanks to the reviewers and editor-in-chief of the journal for their valuable comments and suggestions, which indeed helped to improve the content of the manuscript.

\section{Supporting information}

Additional Supporting Information is available online at the publisher's website.

Methods S1

References S1

Table S1 


\section{Supplementary material}

To view supplementary material for this article, please visit https://doi.org/10.1017/S0967199417000545

\section{References}

Andersen, C.B., Sakaue, H., Nedachi, T., Kovasina, K.S., Clayberger, C., Conti, M. \& Roth, R.A. (2003). Protein kinase $\mathrm{B} / \mathrm{Akt}$ is essential for the insulin but not progesterone stimulated resumption of meiosis in Xenopus oocyte. Biochem. J. 369, 227-38.

Bagowski, C.P., Myers, J.W. \& Ferrell, J.E. Jr. (2001). The classical progesterone receptor associates with p42 MAPK and is involved in phosphatidylinositol 3-kinase signaling in Xenopus oocytes. J. Biol. Chem. 276, 37708-14.

Chaturvedi, D., Poppleton, H.M., Stringfield, T., Barbier, A. \& Patel, T.B. (2006). Subcellular localization and biological actions of activated RSK1 are determined by its interactions with subunits of cyclic AMP-dependent protein kinase. Mol. Cell. Biol. 26, 4586-600.

Conti, M., Andersen, C.B., Richard, F., Mehats, C., Chun, S-Y., Horner, K., Jin, C. \& Tsafriri, A. (2002). Role of cyclic nucleotide signaling in oocyte maturation. Mol. Cell. Endocrinol. 187, 153-9.

Cook, S.J. \& McCormick, F. (1993). Inhibition by cAMP of Ras-dependent activation of Raf. Science 262, 106972 .

Crespo, P., Xu, N., Simonds, W.F. \& Gutkind, J.S. (1994). Rasdependent activation of MAP kinase pathway mediated by G-protein beta gamma subunits. Nature 369, 41820.

Daar, I., Yew, N. \& Vande Woude, G.F. (1993). Inhibition of mos-induced oocyte maturation by protein kinase A. J. Cell. Biol. 120, 1197-202.

Das, D., Khan, P.P. \& Maitra, S. (2013). Participation of PI3kinase/Akt signalling in insulin stimulation of p34cdc2 activation in zebrafish oocyte: Phosphodiesterase 3 as a potential downstream target. Mol. Cell. Endocrinol. 374, 46-55.

Das, D., Khan, P.P. \& Maitra, S. (2017). Endocrine and paracrine regulation of meiotic cell cycle progression in teleost oocytes: cAMP at the centre of complex intraoocyte signalling events. Gen. Comp. Endocrinol. 241, 33-40.

Das, D., Nath, P., Pal, S., Hajra, S., Ghosh, P. \& Maitra, S. (2016b). Expression of two insulin receptor subtypes, insra and insrb, in zebrafish (Danio rerio) ovary and involvement of insulin action in ovarian function. Gen. Comp. Endocrinol. 239, 21-31.

Das, D., Pal, S. \& Maitra, S. (2016a). Releasing prophase arrest in zebrafish oocyte: synergism between maturational steroid and Igf1. Reproduction 151, 59-72.

Dumaz, N. \& Marais, R. (2003). Protein kinase A blocks Raf-1 activity by stimulating 14-3-3 binding and blocking Raf-1 interaction with Ras. J. Biol. Chem. 278, 2981923.

Eyers, P.A., Liu, J., Hayashi, N. R., Lewellyn, A.L., Gautier, J. \& Maller, J.L. (2005). Regulation of the G(2)/M transition in Xenopus oocytes by the CAMP-dependent protein kinase. J. Biol. Chem. 280, 24339-46.
Faerge, I., Terry, B., Kalous, J., Wahl, P., Lessl, M., Ottesen, J.L., Hyttel, P. \& Grøndahl, C. (2001). Resumption of meiosis induced by meiosis-activating sterol has a different signal transduction pathway than spontaneous resumption of meiosis in denuded mouse oocytes cultured in vitro. Biol. Reprod. 65, 1751-8.

Ferrell, J.E. (1999). Xenopus oocyte maturation: new lessons from a good egg. BioEssays 21, 833-42.

Filardo, E.J., Quinn, J.A., Frackelton, A.R. \& Bland, K.I. (2002). Estrogen action via the G-protein-coupled receptor, GPR30: stimulation of adenylyl cyclase and cAMP-mediated attenuation of the epidermal growth factor receptor-to-MAPK signalling axis. Endocrinology 16, 70-84.

Funaki, C., Hodges, R.R. \& Dartt, D.A. (2010). Identification of the Raf-1 signalling pathway used by cAMP to inhibit $\mathrm{p} 42 / \mathrm{p} 44$ MAPK in rat lacrimal gland acini: role in potentiation of protein secretion. Invest. Ophthalmol. Vis. Sci. 51, 6321-8.

Gao, X. \& Patel, T.B. (2009). Regulation of protein kinase A activity by p90 ribosomal S6 kinase 1. J. Biol. Chem. 284, 33070-8.

Ge, W. (2005). Intrafollicular paracrine communication in the zebrafish ovary: the state of the art of an emerging model for the study of vertebrate folliculogenesis. Mol. Cell. Endocrinol. 237, 1-10.

Gerits, N., Sergiy, K., Shiryaev, A., Johannessen, M. \& Moens, U. (2008). Relations between the mitogen-activated protein kinase and the cAMP-dependent protein kinase pathways: Comradeship and hostility. Cell Signal 20, 1592-607.

Grader-Beck, T., van Puijenbroek, A.A.F.L., Nadler, L.M. \& Boussiotis, V.A. (2003). cAMP inhibits both Ras and Rap1 activation in primary human $\mathrm{T}$ lymphocytes, but only Ras inhibition correlates with blockade of cell cycle progression. Blood 101, 998-1006.

Gross, S.D., Lewellyn, A.L. \& Maller, J.L. (2001). A constitutively active form of the protein kinase p90Rsk1 is sufficient to trigger the $\mathrm{G}_{2} / \mathrm{M}$ transition in Xenopus oocytes. J. Biol. Chem. 276, 46099-103.

Haider, S. \& Baqri, S.S.R. (2002). Role of cyclic AMPdependent protein kinase in oocyte maturation of the catfish, Clarias batrachus. J. Exp. Zool. 292, 587-93.

Hajra, S., Das, D., Ghosh, P., Pal, S., Nath, P. \& Maitra, S. (2016). Regulation of recombinant human insulin-induced maturational events in Clarias batrachus (L.) oocytes in vitro. Zygote 24,181-94.

Hanna, R., Pang, Y., Thomas, P. \& Zhu, Y. (2006). Cell surface expression, progestin binding, and rapid nongenomic signaling of zebrafish membrane progestin receptors alpha and beta in transfected cells. J. Endocrinol. 190, 24760.

Hanna, R.N. \& Zhu, Y. (2011). Controls of meiotic signaling by membrane or nuclear progestin receptor in zebrafish follicle enclosed oocytes. Mol. Cell. Endocrinol. 337, 80-8.

Hong, K., Lou, L., Gupta, S., Ribeiro-Neto, F. \& Altschuler, D.L. (2008). A Novel Epac-Rap-PP2A Signaling Module Controls cAMP-dependent Akt regulation. J. Biol. Chem. 283, 23129-38.

Kajiura-Kobayashi, H., Yoshida, N., Sagata, N., Yamashita, M. \& Nagahama, Y. (2000). The Mos/MAPK pathway is involved in metaphase II arrest as a cytostatic factor but 
is neither necessary nor sufficient for initiating oocyte maturation in goldfish. Dev. Genes Evol. 210, 416-25.

Kalous, J., Solc, P., Baran, V., Kubelka, M., Schultz, R.M. \& Motlik, J. (2006). PKB/AKT is involved in resumption of meiosis in mouse oocytes. Biol. Cell. 98, 111-23.

Khan, P.P. \& Maitra, S. (2013). Participation of cAMPdependent protein kinase and MAP kinase pathways during Anabas testudineus oocyte maturation. Gen. Comp. Endocrinol. 181, 88-97.

Kim, S., Jee, K., Kim, D., Koh, H. \& Chung, J. (2001). Cyclic AMP inhibits Akt activity by blocking the membrane localization of PDK1. J. Biol. Chem. 276, 12864-70.

Kondo, T., Yanagawa, T., Yoshida, N. \& Yamashita, M. (1997). Introduction of cyclin B induces activation of the maturation-promoting factor and breakdown of germinal vesicle in growing zebrafish oocytes unresponsive to the maturation inducing hormone. Dev. Biol. 190, 142-52.

Liang, C-G., Su, Y-Q., Fan, H-Y., Schatten, H. \& Sun, Q-Y. (2007). Mechanisms regulating oocyte meiotic resumption: roles of mitogen-activated protein kinase. Mol. Endocrinol. 21, 2037-55.

Lou, L., Urbani, J., Ribeiro-Neto, F. \& Altschuler, D.L. (2002). cAMP Inhibition of Akt is mediated by activated and phosphorylated Rap1b. J. Biol. Chem. 277, 32799-806.

Lowry, O.H., Rosebrough, N.J., Farr, A.E. \& Randall, R.J. (1951). Protein measurement with folin phenol reagent. J. Biol. Chem. 193, 265-75.

Lu, Q., Smith, G.D., Chen, D.Y., Yang, Z., Han, Z.M., Schatten, H. \& Sun, Q.Y. (2001). Phosphorylation of mitogenactivated protein kinase is regulated by protein kinase C, cyclic 3',5'-adenosine monophosphate, and protein phosphatase modulators during meiosis resumption in rat oocytes. Biol. Reprod. 64, 1444-50.

Maitra, S., Das, D., Ghosh, P., Hajra, S., Roy, S.S. \& Bhattacharya, S. (2014). High cAMP attenuation of insulinstimulated meiotic G2-M1 transition in zebrafish oocytes: Interaction between the cAMP-dependent protein kinase (PKA) and the MAPK3/1 pathways. Mol. Cell. Endocrinol. 393, 109-19.

Manning, B.D. \& Cantley, L.C. (2007). AKT/PKB Signaling: Navigating Downstream. Cell 129, 1261-74.

Mood, K., Bong, Y.S., Lee, H.S., Ishimura, A. \& Daar, I.O. (2004). Contribution of JNK, Mek, Mos and PI-3K signaling to GVBD in Xenopus oocytes. Cell. Signal. 16, 631-42.

Moore, M.J., Kanter, J.R., Jones, K.C. \& Taylor, S.S. (2002). Phosphorylation of the catalytic subunit of protein kinase A. Autophosphorylation versus phosphorylation by phosphoinositide-dependent kinase-1. J. Biol. Chem. 277, 47878-84.

Murga, C., Laguinge, L., Wetzker, R., Cuadrado, A. \& Gutkind, J.S. (1998). Activation of Akt/protein kinase B by G-protein-coupled receptors. J. Biol. Chem. 273, 19080-5.

Nader, N., Courjaret, R., Dib, M., Kulkarni, R.P. \& Machaca, K. (2016). Xenopus oocyte prophase I meiotic arrest is released independently from a decrease in cAMP levels or PKA activity. Development 143, 1926-36.

Nagahama, Y. \& Yamashita, M. (2008). Regulation of oocyte maturation in fish. Dev. Growth Differ. 50, S195-219.

Nagahama, Y. (1997). 17 $\alpha$,20 $\beta$-dihydroxy-4-pregnen-3-one, a maturation inducing hormone in fish oocytes: mechanism of synthesis and action. Steroids 62, 190-6.
Okumura, E., Fukuhara, T., Yoshida, H., Hanada, S.S., Kozutsumi, R., Mori, M., Tachibana, K. \& Kishimoto, T. (2002). Akt inhibits Myt1 in the signaling pathway that leads to meiotic G2/M-phase transition. Nature Cell Biol. 4, 111-6.

Pace, M.C. \& Thomas, P. (2005a). Activation of a pertussis toxin-sensitive, inhibitory G-protein is necessary for steroid-mediated oocyte maturation in spotted seatrout. Dev. Biol. 285, 70-9.

Pace, M.C. \& Thomas, P. (2005b). Steroid-induced oocyte maturation in Atlantic croaker (Micropogonias undulatus) is dependent on activation of the phosphatidylinositol 3kinase/Akt signal transduction pathway. Biol. Reprod. 73, 988-96.

Palmer, A., Gavin, A-C. \& Nebreda, A.R. (1998). A link between MAP kinase and p34cdc2/cyclin B during oocyte maturation: p90rsk phosphorylates and inactivates the p34cdc2 inhibitory kinase Myt1. EMBO J. 17, 5037-47.

Pearson, G., Robinson, F., Gibson, T.B., Xu, B-E., Karandikar, M., Berman, K. \& Cobb, M.H. (2001). Mitogen-activated protein (MAP) kinase pathways: Regulation and physiological functions. Endocr. Rev. 22, 153-83.

Posada, J., Yew, N., Ahn, N.G., Vande Woude, G.F. \& Cooper, J.A. (1993). Mos stimulates MAP kinase in Xenopus oocytes and activate a MAP kinase kinase in vitro. Mol. Cell. Biol. 13, 2546-53.

Poser, S., Impey, S., Xia, Z. \& Storm, D.R. (2003). Brain-Derived Neurotrophic Factor protection of cortical neurons from serum withdrawal-induced apoptosis is inhibited by cAMP. J Neurochem 23, 4420-7.

Pramanick, K., Kundu, S., Paul, S., Mallick, B., Roy Moulik, S., Pal, P. \& Mukherjee, D. (2014). Steroid-induced oocyte maturation in Indian shad Tenualosa ilisha (Hamilton, 1822) is dependent on phosphatidylinositol 3 kinase but not MAP kinase activation. Mol. Cell. Endocrinol. 390, 26-33.

Raman, M., Chen, W. \& Cobb, M.H. (2007). Differential regulation and properties of MAPKs. Oncogene 26, 310012.

Sadler, K.C. \& Ruderman, J.V. (1998). Components of the signaling pathway linking the 1-methyladenine receptor to MPF activation and maturation in starfish oocytes. Dev. Biol. 197, 25-38.

Sagata, N., Daar, I., Oskarsson, M., Schowalter, S.D. \& Vande Woude, G.F. (1989). The product of the mos protooncogene as a candidate 'initiator' for oocyte maturation. Science 245, 643-5.

Schmitt, A. \& Nebreda, A.R. (2002). Inhibition of Xenopus oocyte meiotic maturation by catalytically inactive protein kinase A. Proc. Natl. Acad. Sci. U.S.A. 99, 4361-6.

Selman, K., Petrino, T.R. \& Wallace, R.A. (1994). Experimental conditions for oocyte maturation in the zebrafish, Brachydanio rerio. J. Exp. Zool. 269, 538-50.

Stephens, L.R., Eguinoa, A., Erdjument-Bromage, H., Lui, M., Cooke, F., Coadwell, J., Smrcka, A.S., Thelen, M., Cadwallader, K., Tempst, P. \& Hawkins, P.T. (1997). The $\mathrm{G}$ beta gamma sensitivity of a PI3K is dependent upon a tightly associated adaptor, p101. Cell 89, 105-14.

Sun, Q.Y., Lu, Q., Breitbart, H. \& Chen, D.Y. (1999). CAMP inhibits mitogen-activated protein (MAP) kinase activation and resumption of meiosis, but exerts no effects 
after spontaneous germinal vesicle breakdown (GVBD) in mouse oocytes. Reprod. Fertil. Dev. 11, 81-6.

Thomas, P. (2012). Rapid steroid hormone actions initiated at the cell surface and the receptors that mediate them with an emphasis on recent progress in fish models. Gen. Comp. Endocrinol. 175, 367-83.

Wang, L., Liu, F. \& Adamo, M.L. (2001). Cyclic AMP inhibits extracellular signal-regulated kinase and phosphatidylinositol 3-kinase/Akt pathways by inhibiting Rap1. J. Biol. Chem. 276, 37242-9.

Weber, G.M. \& Sullivan, C.V. (2001). In vitro hormone induction of final oocyte maturation in striped bass (Morone saxitalis) follicles is inhibited by blockers of phosphatidylinositol 3-kinase activity. Comp. Biochem. Physiol. B 129, 467-73.

Yoshikuni, M. \& Nagahama, Y. (1994). Involvement of an inhibitory G-protein in the signal transduction pathway of maturation-inducing hormone $(17 \alpha, 20 \beta$ dihydroxy-4-pregnen-3-one) action in rainbow trout (Oncorhynchus mykiss) oocytes. Dev. Biol. 16, 61522.

Zhu, Y., Rice, C.D., Pang, Y., Pace, M. \& Thomas, P. (2003). Cloning, expression, and characterization of a membrane progestin receptor and evidence it is an intermediary in meiotic maturation of fish oocytes. Proc. Natl. Acad. Sci. USA 100, 2231-6. 